\title{
A historical and proteomic analysis of botulinum neurotoxin type/G
}

Rebecca R Terilli ${ }^{1,2,3+}$, Hercules Moura ${ }^{1 \dagger}$, Adrian R Woolfitt', Jon Rees ${ }^{1}$, David M Schieltz ${ }^{1}$ and John R Barr ${ }^{1 *}$

\begin{abstract}
Background: Clostridium botulinum is the taxonomic designation for at least six diverse species that produce botulinum neurotoxins (BoNTs). There are seven known serotypes of BoNTs (/A through/G), all of which are potent toxins classified as category A bioterrorism agents. BoNT/G is the least studied of the seven serotypes. In an effort to further characterize the holotoxin and neurotoxin-associated proteins (NAPs), we conducted an in silico and proteomic analysis of commercial BoNT/G complex. We describe the relative quantification of the proteins present in the/G complex and confirm our ability to detect the toxin activity in vitro. In addition, we review previous literature to provide a complete description of the BoNT/G complex.

Results: An in-depth comparison of protein sequences indicated that BoNT/G shares the most sequence similarity with the/B serotype. A temperature-modified Endopep-MS activity assay was successful in the detection of BoNT/G activity. Gel electrophoresis and in gel digestions, followed by MS/MS analysis of/G complex, revealed the presence of four proteins in the complexes: neurotoxin (BoNT) and three NAPs-nontoxic-nonhemagglutinin (NTNH) and two hemagglutinins (HA70 and HA17). Rapid high-temperature in-solution tryptic digestions, coupled with MS/MS analysis, generated higher than previously reported sequence coverages for all proteins associated with the complex: BoNT 66\%, NTNH 57\%, HA70 91\%, and HA17 99\%. Label-free relative quantification determined that the complex contains 30\% BoNT, 38\% NTNH, 28\% HA70, and 4\% HA17 by weight comparison and 17\% BoNT, 23\% NTNH, 42\% HA70, and 17\% HA17 by molecular comparison.

Conclusions: The in silico protein sequence comparisons established that the/G complex is phenetically related to the other six serotypes of C. botulinum. Proteomic analyses and Endopep-MS confirmed the presence of BoNT and NAPs, along with the activity of the commercial/G complex. The use of data-independent $M S^{E}$ data analysis, coupled to label-free quantification software, suggested that the weight ratio BoNT:NAPs is 1:3, whereas the molar ratio of BoNT:NTNH:HA70:HA17 is 1:1:2:1, within the BoNT/G progenitor toxin.
\end{abstract}

\section{Background}

Clostridium botulinum is the taxonomic designation for at least six diverse species that produce botulinum neurotoxins (BoNTs). This heterologous species is further classified into six metabolically distinct groups (I-VI). The groups include the toxin-forming strains of C. botulinum, C. butyricum, C. baratii, and C. argentinense [1]. C. botulinum is a spore-forming anaerobic bacteria which produces toxins that are lethal to humans and animals, and are classified as category A bioterrorism

\footnotetext{
*Correspondence: jbarr@cdc.gov

+ Contributed equally

${ }^{1}$ Centers for Disease Control and Prevention, National Center for Environmental Health, Division of Laboratory Sciences, 4770 Buford Hwy, N. E., Atlanta, GA 30341, USA

Full list of author information is available at the end of the article
}

agents [2,3]. BoNTs target the Soluble NSF Attachment Protein Receptors (SNARE) complex of proteins in the synaptic vesicle and plasma membranes, preventing acetylcholine from being released causing botulism (Figure 1) [3]. Seven immunologically distinct BoNT serotypes (/A through/G) have been described $[1,3]$.

Botulinum neurotoxin G (BoNT/G) is the least studied of the seven serotypes. BoNT/G-producing organisms were first isolated by Gimenez and Ciccarelli in 1969 from soil samples taken from a cornfield in the Mendoza Province of Argentina [4]. The investigators indicated that a novel strain of bacterium produced an antigenically specific, heat-labile botulinum-like toxin that was not neutralized by any of the known botulinum antisera. The antitoxin developed using this strain only 

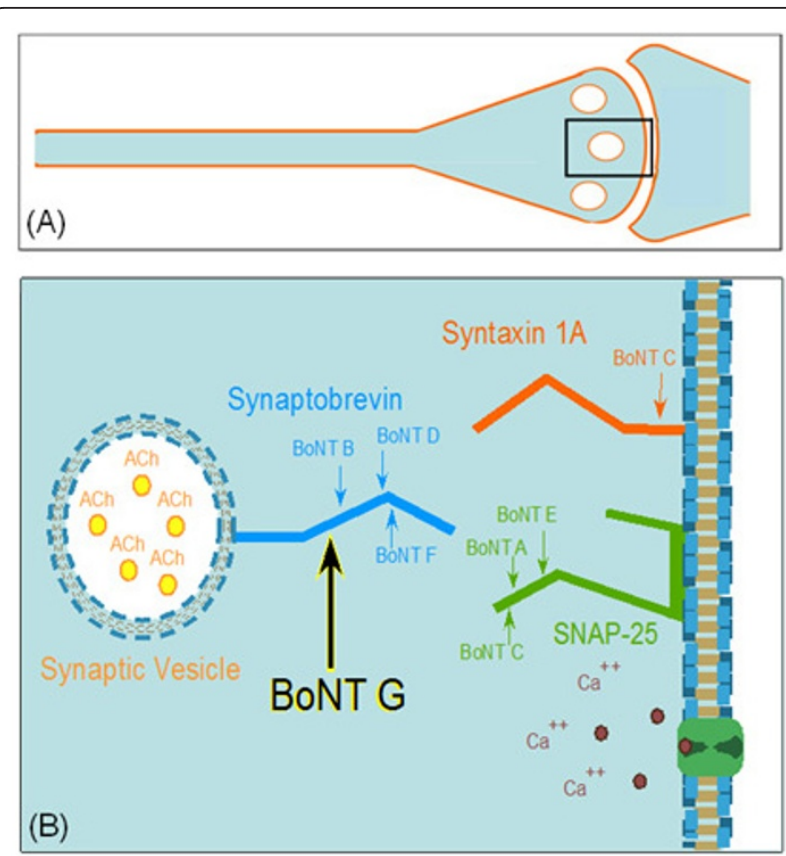

Figure 1 Graphical representation of the cell and peptide targets of Botulinum neurotoxin. 1(A) is a representation of the Synaptic cleft where BoNT enters the eukaryotic nerve cell. 1(B) displays the position on the synaptobrevin-2 (VAMP-2) protein where BoNT/G cleaves, stopping the synaptic vesicle from releasing acetylcholine, inhibiting nerve impulse and causing muscle paralysis. In a healthy cell, synaptobrevin-2 on the synaptic vesicle must interact with syntaxin and synaptosomal-associated protein-25 (SNAP-25) on the neuronal membrane for fusion to occur. Fusion allows the nerve impulse to be delivered across the synaptic junction.

neutralized its homologous toxin and showed no activity on any of the other known types of BoNT [4]. Overall, nine strains of type $\mathrm{G}$ producing organisms have been isolated, two from Argentina and seven from Switzerland; none of which have ever been clearly implicated as the cause of paralytic illness or death in humans or animals [5].

Type G organisms are historically associated with the C. botulinum species, because of their ability to produce botulinum neurotoxin [3,4]. However, it is well known that botulinal toxin production is a poor parameter on which to base species identification and that the $C$. botulinum species is a taxonomic collection of several distinct species [3,5-7]. Type/G producing organisms are classified as Clostridium argentinense [5]. This species includes 12 strains of bacteria from the genus Clostridium: nine toxigenic strains and three non-toxigenic strains. These strains are genetically and phenotypically distinct from all other strains of C. botulinum and other clostridial species [5].

Two of the three non-toxigenic strains were once classified as C. subterminale, and the third as C. hastiforme.
These strains were often reported to cause serological cross-reactions with type/G producing organisms and the BoNT/G protein in ELISA and Fluorescence Resonance Energy Transfer (FRET) detection assays $[5,8,9]$. The $C$. argentinense species can be distinguished from other asaccharolytic, proteolytic clostridia by a biochemical test that detects the production of a unique derivative of indole [5]. However, to avoid confusion among the medical and scientific communities, $C$. argentinense type/G producing organisms are still referred to as $C$. botulinum type/G [7].

Type/G toxin is produced in culture as a relatively large protein complex (L complex $\sim 500 \mathrm{kDa}$ ) consisting of a neurotoxin (BoNT) and three neurotoxin-associated proteins (NAPs): two hemagglutinins (HA17 and HA70) and a nontoxic-nonhemagglutinin (NTNH) component. In addition, there is a gene expression protein (P21) that is responsible for regulating the expression of the four complex proteins. P21, however, is not associated with the toxin complex itself $[10,11]$. The function of the NAPs has been shown to protect the neurotoxin in harsh environments in order to allow the toxin to enter the synaptic membrane. Once inside the vesicle, the toxin can cleave its specific SNARE complex protein $[3,12]$. BoNT/G is known to cleave the Synaptobrevin protein (VAMP-2) in the SNARE complex (Figure 1B). It is the only toxin known to cleave at a single $\mathrm{Ala}^{81}$ $\mathrm{Ala}^{82}$ peptide bond [13] (Table 1).

Type/G-forming organisms have a relatively low toxigenicity, producing only small amounts of toxin in culture. This characteristic makes it difficult to identify type/G organisms in the presence of other species [14]. The toxin requires tryptic activation to be successfully detected in vitro; this requirement is also associated with toxins produced by non-proteolytic types/B and/F, as well as all strains of type/E [14]. Regardless of BoNT/ G's low toxigenicity in vitro, Rhesus monkeys, chickens, and guinea pigs have demonstrated susceptibility to non-activated toxin when BoNT/G has been administered by various routes [15]. In addition, it has been reported that the ability to produce BoNT/G can be lost from toxigenic strains after several culture passages [16].

Table 1 Peptide Cleavage Products for BoNT/B and/G.

\begin{tabular}{llll}
\hline \multicolumn{3}{l}{ BoNT/B and/G Substrate } & Masses \\
\hline Intact & LSELDDRADALQAGASQFESAAKLKRKYWWKNLK & 4025 \\
/B-NT & LSELDDRADALQAGASQ & & 1759 \\
/B-CT & & FESAAKLKRKYWWKNLK & 2283 \\
/G-NT & LSELDDRADALQAGASQFESA & & 2281 \\
/G-CT & & AKLKRKYWWKNLK & 1762 \\
\hline
\end{tabular}

The predicted cleavage products and the masses of the substrate and product peptides for both/B and/G are shown. The substrate peptide was derived from the human Synaptobrevin-2 (VAMP-2) protein. Note that/B and/G cleave 4 amino acids apart. 
The loss is thought to occur because the complete nucleotide sequence of the BoNT/G gene, and the NAPs, are found on a 81-MDa plasmid and not on the chromosome [16,17] (Figure 2). Of the seven serotypes, the BoNT/G nucleotide sequence has the most similarity to that of BoNT/B, as previously described [17].

Although BoNT/G is the least studied serotype of $C$. botulinum, previous reports have described a digestion method, two protein detection assays, and an activity detection assay. Hines et al. were the first to apply a proteomics approach for BoNT/G. The authors used a 16-hour digestion method, followed by high-pressure liquid chromatography (HPLC) coupled to mass spectrometry (MS). The method returned limited recovery of peptides and protein sequence coverage. However, it provided enough information to distinguish the proteins associated with the BoNT/G complex [18]. Glasby and Hatheway described the potential use of fluorescentantibody reagents to identify C. botulinum type/G producing strains, but they encountered cross-reactivity issues with similar species of non-toxigenic clostridia [9]. Lewis et al. reported an ELISA BoNT/G protein detection assay that was able to detect low concentrations of the BoNT/G proteins. The assay, however, also suffered from issues of cross-reactivity with similar nontoxigenic Clostridium species [8]. Finally, we have previously described a mass spectrometry-based activity detection assay, the Endopep-MS method, which was developed to detect the activity of BoNTs in vitro against toxin-specific substrate peptides. This method was successful at detecting all seven BoNT serotypes [19].

Proteomics has been used to study changes after treatment with BoNT/A on suprachiasmatic nucleus [20], on the thyroarytenoid muscle [21], and of C3 exoenzyme from C. botulinum [22], but there are very few reports on the BoNT proteome. In the present report, we detail proteomics methods that were successfully applied to the analysis of BoNT/G complex and thus further the understanding of the serotype. We confirmed the detection of toxin activity by use of the Endopep-MS method.
The application of a rapid digestion method, coupled with nano ultra-pressure liquid chromatography tandem mass spectrometry (nUPLC-MS/MS), was successful at obtaining a greater percentage of amino acid sequence coverage of each protein associated with the/G complex than was previously reported. In addition, we describe the characterization and relative quantification of the proteins present in the/G complex. We also compare BoNT/G to other BoNT serotypes and discuss the previous literature reports to provide a complete description of the BoNT/G complex.

\section{Results}

\section{Amino acid sequence comparisons confirmed BoNT/G and/B similarity}

Phenetic analysis of the seven available toxin sequences compared revealed that BoNT/G was the most similar to the BoNT/B Okra and the least similar to BoNT/C Stockholm, with a $58.2 \%$ and a $32.9 \%$ sequence similarity, respectively (Figure $3 \mathrm{~A}$, additional file 1 ). To determine the extent to which the/G sequence is shared among toxins in the/B family,/G was compared with 22 different/B strains, including subtypes of/B1,/B2,/B3, bivalent ( $\mathrm{Bv} / \mathrm{A}$ and $\mathrm{Bv} / \mathrm{F})$, and non-proteolytic/B (np/B). Of the 22 sequences,/G shared the most sequence homology with the/B2 Prevot 25 NCASE strain, with an overall $58.9 \%$ sequence similarity (additional file 2 ). In a focused look at the similarities between/G and the/B2 strain, the individual domains of the toxin proteins were compared. The percent similarity returned for each domain were as follows: peptidase (light chain) $60.9 \%$, translocation (heavy chain) $63.8 \%$, binding $\mathrm{N}$-terminal (NT) (heavy chain) 55.3\%, and binding C-terminal (CT) (heavy chain) 52.4\% (Figure 3B). Additional comparison of BoNT/G NAPs with the NAPs of the other six serotypes indicated that not only is the type/G toxin sequence the most similar to/B, but the NAPs sequences for both serotypes do as well. The percent similarity returned for the NAPs were as follows: NTNH 78.3\%, HA70 73.1\% and HA17 58.7\% (Figure 3C-D, additional files 3,4 , and 5).

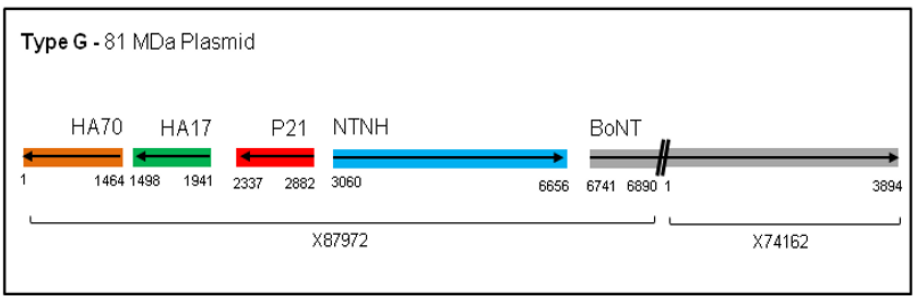

Figure 2 Schematic of Type G 81 MDa Plasmid. This is a visual display of the order and direction in which the genes within the BoNT/G complex are associated along the $81 \mathrm{MDa}$ plasmid. NCBI does not have the gene listed under one accession number but rather is split into two: the NAPs X87972 and the toxin X74162. 

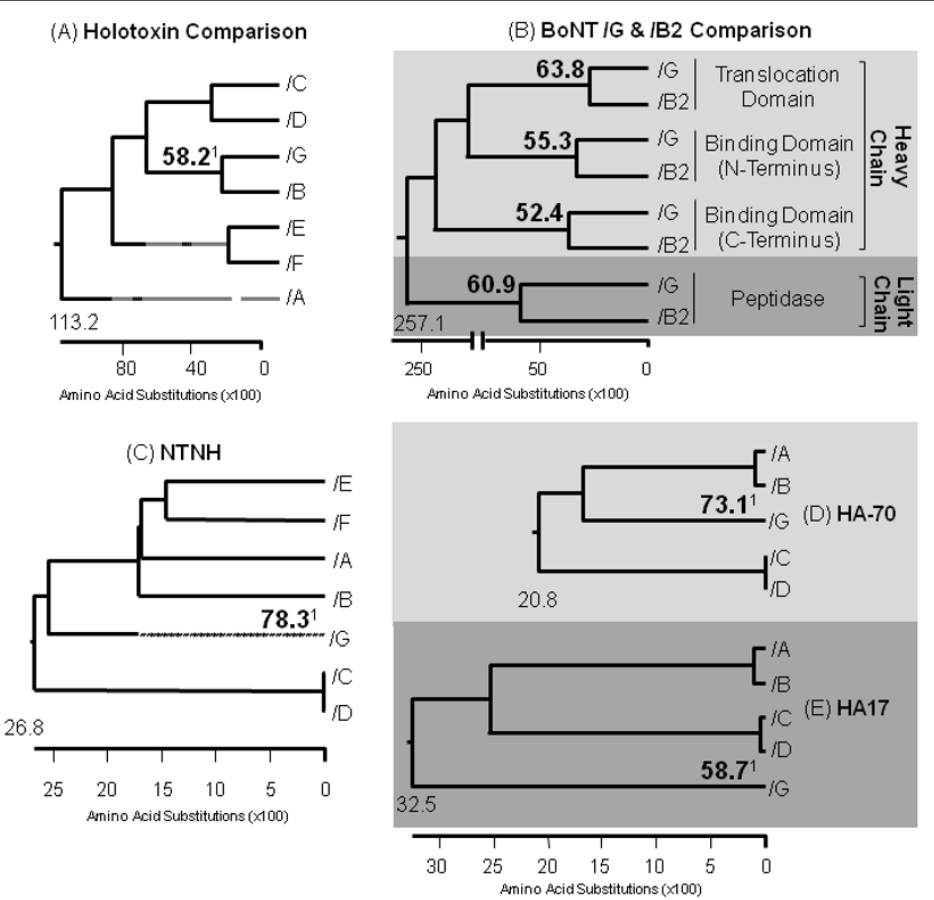

Figure 3 In-depth protein sequence comparisons of the seven BoNT and NAPs. This figure displays the phenetic grouping of: (A) the seven serotypes, most common strains, toxin sequences; (B) individually compared toxin domains of/G and the/B2 Prevot strain, the toxin sequence in the/B family that shares the most similarities with/G; (C) the seven serotypes, most common strains, NTNH sequences; (D) the seven serotypes, most common strains, HA70 sequences; and (E) the seven serotypes, most common strains, HA17 sequences. Of the seven serotypes,/G shares the most similarity with the/B serotype. The percent identity shared between each/G and/B protein or domain is highlighted above'.

\section{Gel LC-MS/MS Analysis identified the four main proteins within the BoNT complex}

Six of the 17 gel slices, tryptically digested overnight and analyzed by use of $\mathrm{nLC}-\mathrm{MS} / \mathrm{MS}$, returned protein matches with high sequence coverage and a $99 \%$ identity confidence when searched by use of PLGS v2.3 and validated with Scaffold v2.1. The four main proteins associated with the botulinum neurotoxin complex were identified in various bands from the gel: BoNT/G, NTNH, HA70, and HA17 (Figure 4).

\section{In solution Tryptic Digestion Analysis improved protein sequence coverage}

The results of the six digests of BoNT/G from both analytical instruments (QTof-Premier and LTQ-Orbitrap) were compiled to determine the greatest percent of sequence coverage of each protein identified: BoNT/G [NCBI, CAA52275], NTNH [NCBI, CAA61228], HA70 [NCBI, CAA61225], and HA17 [NCBI, CAA61226] (Figure $5 \mathrm{~A}-\mathrm{D})$. The percent recovery was determined by combining all unique peptides identified by both nLCMS/MS instruments and calculating the ratio of amino acids identified vs. total amino acids in the protein sequence.

\section{Endopep-MS Analysis confirmed toxin activity}

The results of the Endopep-MS experiments conducted through use of various dilutions of BoNT/G indicated that the optimum temperature for/G activity is $42^{\circ} \mathrm{C}$, not $37^{\circ} \mathrm{C}$ as observed with other BoNT serotypes. Additionally, the experiments indicated that the toxin is the most active, or best activated, when first exposed to a short $10 \mathrm{~min}$ pulse at $47^{\circ} \mathrm{C}$ and then continuously incubated at $42^{\circ} \mathrm{C}$ for $120 \mathrm{hrs}$. The detection of the $2281 \mathrm{~m} /$ $z(\mathrm{NT})$ and $1762 \mathrm{~m} / z(\mathrm{CT})$ product ions in each experiment confirmed that the lots of commercial toxin used were active.

\section{Relative quantification of type G toxin and NAPs was determined by use of $\mathrm{MS}^{\mathrm{E}}$}

Label-free relative protein quantification was obtained for each component of the type G toxin complex (Table $2)$. When calculated by weight, the BoNT/G complex contained $30 \%$ of toxin, $38 \%$ of NTNH, $28 \%$ of HA70, and $4 \%$ of HA17. These percentages and nanogram amounts indicate that the overall weight ratio of BoNT: NAPs present within the complex is 1:3. The percentages of each molecule present in the complex are as follows: $17.2 \%$ of toxin, $23.1 \%$ of NTNH, $42.0 \%$ HA70, 


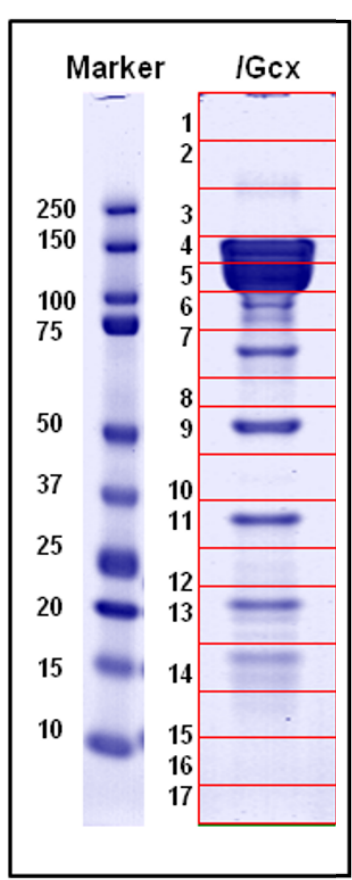

Figure 4 1D SDS-PAGE and in gel digestion analysis of/G complex. This image depicts the All Blue standard (Bio-Rad, CA) and the/G complex after staining with GelCode ${ }^{\mathrm{TM}}$ Blue Safe Protein Stain (Pierce, IL). The lane of interest was cut into 17 segments, digested overnight, analyzed on a nanoLC-MS/MS system, and identified by use of PLGS protein database searching. The proteins identified were BoNT/G (band 4), NTNH (5); HA70 was identified in three bands $(7,9$, and 13$)$ and HA17 in band 14 .

and $17.8 \%$ HA17. These percentages and femtomole amounts indicate a 1:1:2:1 BoNT:NTNH:HA70:HA17 ratio, or a 1:4 BoNT:NAPs ratio, of molecules within the complex.

\section{Discussion}

BoNT/G is the least-studied and the most recently reported of the seven serotypes produced by $C$. botulinum. Although BoNT/G is associated with a distinct species and metabolic group, the toxin shares multiple characteristics with the other six progenitor toxins. The seven serotypes have similar biochemical and molecular mechanisms of cell entry and membrane translocation. They cause disease by inhibiting synaptic transmission as a result of the enzymatic cleavage of the SNARE protein complex. In the present work, we detail the in silico comparison of BoNT/G progenitor toxin proteins to the other six serotypes of $C$. botulinum, as well as methods for the digestion, detection, and relative quantification of BoNT/G and its NAPs.

The comparison of the BoNT/G progenitor toxin with the other six serotypes was completed to determine/G's phenotypic relationship with the other BoNTs. In general, past analyses $[7,10,23]$ have included a comparison at the gene level; this study focuses solely on protein level. While comparisons of toxin and NTNH proteins to select serotypes have been previously described [23], a complete comparison of all/G complex proteins (toxin, NTNH, HA70, and HA17) with the other six serotypes has not been previously reported. Phenetic analysis confirmed that the BoNT/G complex of proteins shared the most similarity with the/B serotype (Figure 3C-E), as previously reported $[10,23]$.

To determine the extent of/G's homology to the/B toxin serotype, we completed an in-depth comparison of six/B subtypes, 22 different accession numbers (Figure $3 \mathrm{~B}$, additional files 2). The comparison of individual domains-translocation domain, binding domain NT, binding domain $\mathrm{CT}$, and peptidase-revealed the area of the toxin in which/G shares the greatest (translocation domain) and least (binding domain CT) similarity. Overall, each domain compared, between the two toxins, is greater than $50 \%$ similar. This comparison helped to determine which substrate peptide would be optimal to test the activity of/G. Although there are no direct indications that sequence similarity would imply overall identical functionality, similar sequences would allow similar crystal structures to form, suggesting similar functionality [24]. It is currently known that both BoNT/B and/G cleave the Synaptobrevin protein;/B cleaves a $\mathrm{Gln}^{76}-\mathrm{Phe}^{77}$ bond and/G an $\mathrm{Ala}^{81}-\mathrm{Ala}^{82}$ bond five amino acids downstream (Table 1). Because the cleavage sites of both toxins are relatively near one another-thus the similarity of their binding domain sequences and therefore structures-the same peptide substrate currently used to test/B activity was used to test/G activity [19].

In order to confirm that the commercial BoNT/G complex was active and therefore could be considered analogous to the toxin complex found in clinical samples, various dilutions of the commercial toxin were tested using the Endopep-MS method previously described (Figure 6) [19]. In addition to confirming the toxin's activity, the Endopep-MS experiments indicated a new optimum temperature for/G activity. When reactions were pulsed at $47^{\circ} \mathrm{C}$ for $10 \mathrm{~min}$, followed by incubation at $42^{\circ} \mathrm{C}$ for at least eight hours-as opposed to $37^{\circ} \mathrm{C}$ for a minimum of $17 \mathrm{hr}-$ an increase in activity and in the quality of mass spectra produced was observed. Other serotypes of BoNT (/C and/D) are often associated with botulism in animals, avians, equines, and bovines, whose body temperatures are higher than those of humans. BoNT/G has yet to be associated with botulism in a particular organism; however, it is possible that/G would be more effective at causing disease in an organism with a higher body temperature than that of humans, similar to BoNT/C and/D. 


\section{(A) IG $66 \%$ coverage}

1 MPUNIKXFNY MDPINRDDII MRIEPFHDPGP GTYYKAFRII DRTHIVPERF 51 TYGFQPDQFN ASTGVFSKDV YEYYDPTYLK TDAEKDKKFLK TMIKLFNRIN 101 SKPSGQRLLD MTVDAIPYLG KASTPPDKFA ANVANVSIIKK KIIQPGAEDO 151 IKGLUTRLII FGPGPVLSDN FTDSIIDNAG SPISEGFGAR MMIRFCPSCL 201 HVFHNOEEKK DTSIFSRRAY FADPALTLMH ELIHVLHGLY GIKISMLPIT 251 PNTKEFFMQH SDPVQAEELY TFGGHDPSVI SPSTDARIYN KALQMFQDIA 301 MRLHIVSSA Q GSGIDISLYK QIYKNKYYFV EDPHGKYSVD KDKFDKLYKA 351 LIFGFTETRL AGEYGIKTRY SYF SEYLPPI KTEKLLDNTI YTQNEGFNIA 401 SKNLKTEFNG QMKANNKEAY EEISLEKLVI YRIAMCKPVH YKNTGKSEQC 451 IIVNNEDLFF IANKDSFSKD LAKAETIAYN TONNTIENNF SIDQLILDND 501 LSSGIDLPNE NTEPFTNFDD IDIPVYIKQS ALKKIFVDGD SLFEYLHAQT 551 FPSHIERLQL THSLMDALRN NNKVYTFFST RLVEKANTVV GASLFVHWVK 601 GVIDDFTSES TQKSTIDKVS DVSIIIPYIG PALHVGNETA KENFKNAFEI 651 GGMAILMEF I PELIVPIVGF FTLESTVGNK GHIMITISHA LKKRDQRWTD 701 MYGLIVSQWL STVNTQFYTI KEFMYMALNN QSQAIEKIIE DQYIRYSEED

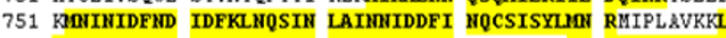
801 KDFDDRLKRD LLEYIDTHEL YLLDEVIILK SKVNRHLKDS IPFDLSLYTK 851 DTILIQVFNN YISNISSNAI LSLSYRGGRL IDSSGYGATM NVGSDVIFHD 901 IGNGOFKLIM SENSHITAHO SKFVVYDSMF DNFSINFUVR TPKYNNNDIO 951 TYLQNEYTII SCIKNDSGUK VSIKGNRIIH TLIDVMAKSK SIFFEYSIKD 1001 MISDYINKHF SITITKDRLG KANIYINGSL KKSEKILMLD RINSSHDIDF 1051 KLINCTDTTK FUWIKDFNIF GRELNATEVS SLYHIQSSTN TLKDFUGNPL 1101 RYDTQYYLFN QGIONIYIKY FSKASTIGETA PRTHFMMAAI HYQMLYLGLR 1151 FIIKKASNSR HIMIDHIVRE GDYIYLNIDH ISDESYRVYV LVYSKEIQTO 1201 LFLAPIMDDP TFYDVLQIKK YYEKTTYNCQ ILCEKDTKTF GLFGIGKFVK 1251 DYGYVWDTYD NYFCISQUYL RRISENIMKL RLGCNWQF IP VDEGUTE

\section{(C) HA17 99\% coverage}

1 MTAERTFLPH GWYKIKSIFS DSLYLTPLSE IITFLNTSSE MNQKHKLQYV 51 EEKAIAYKISA IAQPDKYLTY WSSQFIVLKA IGDSTALENY HIPYKIASN 101 YIITKLKEYD KAHDIYDLNG DISDQPLLLQ QLFYYEKSNQ IFIFEKI

\section{(B) NTNH $57 \%$ coverage} 1 RKINSILTII SPIDHKAVVI VRARETSKFF KAFKVAPHIH VAPERYYGES
51 LSIEESKKVI GGVYDSHFLS QRTEKDKFLO AIITLLKRIM SHIAGEKLLS 101 LVSTAIPFPY GYIGGGYYCP NIVTFGSTIK YNKKINSLIS TTIPFPYGG 151 RETHYLSSKD TEMFYAAHTV IFGPGANIVE BITVFYKKED AENGMGTMAE 201 ICFQPFLTYK YDQFYVDPAL ELMECLIKSL YFLYGIKPNN NLTVPYRLRH 251 ELSNIEFSOL SIVDLLISGG IDSKFINTDP YHFIDSYFSH AKTTFEEHKS 301 IYETEIKGM AIGRDIKLRL KQKFOTTVID THQLHLDYFS KEFOMAIPYP 351 FNNAL KYYYR KEYYKIDYPE KYSIAGFVDG OLNTOLSLSD KNOYIIMKPE 401 ETVRLISEM ISURSHIYG DGLKYTTDHF YSTYKIPYNR AYEYHFMNSS 451 TSSLENVNVE EISHIPEIID IMPYRENSDI FSPVEMIIET KEVNTKTPUP 501 INYLOROIPN NEEFTLSSDF SOVVSYKTOS LVYSFL SWVI SYIDSYKDTI 501 INYLQAQIPN NEEFTLSSDF SQVVSYKYOS LVYSFLSNVI SYLDSVKDTI 551 PIDTDEKYYL WLREIFRNYS FDITAIEEIN TSCGINKVVS HFGKALHILI 601 TSHSFVKEFK BLGPISLINK KERL SAPIIE VMEIPHDIIL G LSLKDLNEKL 651 FHIYLKAILY FKKVYFSFLD QWUTEYYSQY FGLICMAKQS ILAQENLIKK 701 IVQKKLSDLS KOSHISHEKL BINARLTTEKT FIDLSHOSQI ANONIMATLLH 751 KAAICVFESN IYPKF ISFME QYINNINIKT TAFIRKCTNI TEKEKLOLIH 801 ONTFMILDFE FFDIOTIERL LTSETRLIIK EKTSPYDLLL FSLQEADRKV 851 IKDISGKDTL VQYSDTIDLS YGVIGDALYL KEPNQSVNFS NNIFENGLTN 901 SFSICFULRN LGQDNLSSNL IGNIVNNCGW QIYFENNGLV FSMVDCNGNE 951 KUIYLSDVLS KYHYYISVSV DRLRNKLLIF INDKL IVNES IEQILNIYSS 1001 NIISLVNENN PICIEELSIL NKALTSEEVL WSYFTMLMIS YIRDSYGARL 1051 EYNKNYELYN YVFPENSLYE VIENNNMYLS IKNIKATNIL GAKFKLINTD 1101 ESKOYVQKUD EVIICVLGDT EKYADIQAGN BRIQLVWSKD KARKIIVNNN 1151 IFRPNCVLFS YNNKXLSLSL RNRNYNHHIC NDNSFIPKMA HLHILKKI

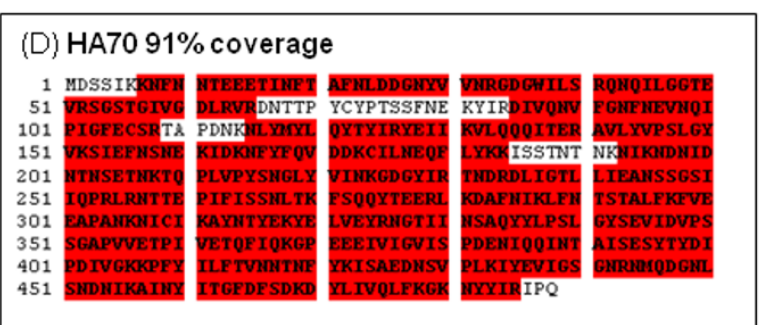

Figure 5 Sequence coverage returned from in solution tryptic digests. The four main proteins that are associated with the BoNT/G complex and the percent of each sequence that was returned after digestion are highlighted above. The percent recovery was determined by combining all unique peptides returned from two nanoLC-MS/MS instruments and calculated by use of the number of amino acids recovered vs. total amino acids in the protein sequence. (A) BoNT/G 66\% [NCBI, CAA52275] (B) NTNH 57\% [NCBI, CAA61228] (C) HA17 99\% [NCBI, CAA61226] (D) HA70 91\% [NCBI, CAA61225]

Proteomic strategies and analyses used in this study were important to help define the characteristics of proteins associated with the BoNT/G complex. The 1DSDS PAGE analysis confirmed the presence of the four expected complex proteins (BoNT, NTNH, HA70, and HA17), with relatively high sequence coverage for in gel digestion (Figure 4). As expected the proteins, P21 and HA33, were not identified. P21, a positive regulator of gene expression, lies just upstream of NTNH on the toxin plasmid (Figure 2) [10]. The purpose of P21, in complex development, is not completely understood and previous reports have not identified it as part of the/G complex [11]. HA33, a hemagglutinin component, is not found on the/G plasmid. The lack of evidence of the protein's presence further endorsed the theory that, unlike the other serotypes, HA33 is not associated with the/G complex [10]. Two gel slices (Figure 4; \#6 and 11) out of 17 visually had protein but did not return any identifiable peptides when digested and analyzed. This could be due to a number of factors: the protein was relatively difficult to digest, there was not a sufficient amount of protein to digest, the sequence was not present in the database used, or post-translational modifications (PTMs) altered the protein sequence and did not

Table 2 Relative quantification of Type G toxin and NAPs.

\begin{tabular}{|c|c|c|c|c|c|c|}
\hline \multirow[t]{2}{*}{ Protein Description } & \multirow[t]{2}{*}{ Accession \# } & \multirow[t]{2}{*}{ Avg Mass (kDa) } & \multicolumn{2}{|c|}{ Amount OnColumn } & \multicolumn{2}{|c|}{$\%$ in the Complex } \\
\hline & & & femtomoles & nanograms & molecules & weight \\
\hline BoNT/G & CAA52275 & 149034 & 110.0 & 16.4 & 17.2 & 30.4 \\
\hline NTNH type G & CAA61228 & 139083 & 147.6 & 20.5 & 23.1 & 38.1 \\
\hline HA-70 (III) type G & CAA61225 & 55791 & 268.5 & 14.9 & 42.0 & 27.8 \\
\hline HA-17 (II) type $G$ & CAA61226 & 17372 & 113.8 & 1.9 & 17.8 & 3.7 \\
\hline
\end{tabular}

The proteins identified in the/G complex, NCBI accession numbers, and average masses are shown, in addition to the calculated amounts on column, femtomoles and nanograms, and the percent of each protein, by weight and molarity, within the BoNT complex. 


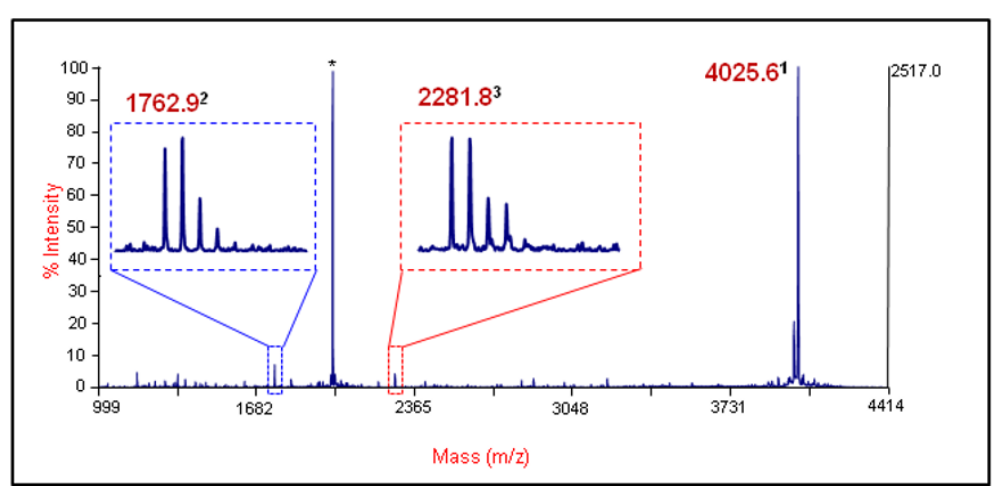

Figure 6 Endopep-MS method confirmation of commercial BoNT/G activity. This is a representative spectrum indicating BoNT/G activity on a specific substrate peptide. ${ }^{1}$ Intact substrate, ${ }^{2} \mathrm{C}$-Terminus product mass 1762.9 , and ${ }^{3} \mathrm{~N}$-Terminus product mass 2281.8 . The sequences are listed in Table 1. *Indicates double charged ion of the intact substrate peptide.

allow for identification. The SDS-Page gel and in gel digestions confirmed visually and analytically which proteins are present in the commercial toxin complex and allowed us to continue to in solution digestions with some prior knowledge of which proteins should be identified.

As anticipated, the same proteins that were identified with the in gel digestions were also identified in the analysis of the in solution digestions. The four main complex components- BoNT, NTNH, HA70, and HA17were all identified with high confidence, and returned a large number of peptides. Hines et al. reported the use of a reduction and alkylation overnight digestion method that produced sequence coverages of $16 \%$ for BoNT, $10 \%$ for NTNH, $38 \%$ for HA70, and $49 \%$ for HA17 [18]. The method used in our study allowed the recovery of more than four times the sequence coverage for BoNT at $66 \%$, more than five times for NTNH at $57 \%$, and more than double for both HA70 and HA17 at $91 \%$ and $99 \%$, respectively.

BoNT complexes are difficult to digest in solution [18]. This rapid high-temperature digestion method does not involve reduction and alkylation, unlike classical methods; instead, it uses an acid labile surfactant to solubilize the hydrophobic proteins. The increased solubility allows a denatured protein to be more susceptible to tryptic digestion, thereby increasing the rate of digestion and the number of tryptic peptides produced [25]. It has also been previously reported that the use of high temperature for a short period of time is the best condition for the enzymatic activity of trypsin [26].

This BoNT complex digestion method, in addition to analysis of the samples on two different electrospray (ESI) MS instruments using data-dependent (DDA) and data-independent $\mathrm{MS}^{\mathrm{E}}$ analysis, allowed for the detection of a greater number of peptides for each protein, leading to a greater overall sequence coverage than had previously been reported. This sequence coverage lends insight into the complex proteins being studied. A high percentage of sequence coverage indicates that there are few PTMs associated with the proteins, as well as no truncation. The presence of PTMs has been known to compromise protein identification, and truncated proteins do not function as expected.

In addition to providing enhanced sequence coverage, the use of data-independent $M S^{\mathrm{E}}$ analysis and label-free quantification software allowed us to relatively quantify the amount of each protein present in the BoNT/G complex (Table 2). This quantification method has the advantage of being able to provide accurate estimates of relative protein abundance (often within $30 \%$ of the known values on most identified proteins in a mixture, without the much more rigorous requirements of targeted protein quantification methods. A percentage of abundance (by weight and molecules, separately) of each protein within the complex was determined, as well as an overall weight ratio of BoNT:NAPs and a molecular ratio of BoNT:NTNH:HA70:HA17. Analysis of the individual proteins within the complex illustrated that the weight of the toxin $(30.4 \%)$ is almost equivalent to that of HA70 (27.8\%) and about eight percent less than that of NTNH (38\%); whereas HA17 makes up only a minute portion of the overall weight at just $3.7 \%$. Conversely, analysis using molecular amounts indicated that the complex contains an equivalent amount of the toxin, NTNH, and HA17, whereas HA70 is almost twice as abundant. The nanogram and femtomole on column data sets signify a likely overall ratio of 1:3 BoNT:NAPs weight ratio and a 1:1:2:1 BoNT:NTNH:HA70:HA17 molar ratio. As stated earlier, the function of the NAPs has been shown to protect the neurotoxin in harsh environments [12]. Due to this protective ability, in theory, a larger ratio of NAPs:BoNT, ie the greater the number of molecules of NAPs to BoNT, would protect 
more effectively the toxin from the acidic environment of the stomach. This potentially would increase the toxin's effectiveness at penetrating the mucosa of the intestine and entering the blood stream, increasing the toxin's chances of entering the synaptic cell and causing disease. Knowledge of the stoichiometry of proteins within the BoNT complexes would be useful to further understanding of NAPs significance and toxin potency.

\section{Conclusions}

We have presented a detailed in silico comparison of the/G complex of proteins to the other six serotypes in an effort to compare, contrast, and further define the complex's relationship relative to the/B serotype and subtypes within the botulinum toxins. Proteomic analyses, consisting of gel electrophoresis, in gel and in solution digestions, and Endopep-MS, confirmed the presence of BoNT, NTNH, HA70, and HA17 proteins and the activity of the commercial/G complex. We were successful at obtaining high sequence coverage for all four complex proteins by using a rapid, high-temperature digestion method and analysing with two different nLC-MS/MS instruments. The efficiency of this method allowed for a greater recovery of protein sequence and further insight into the complex proteins. The use of data-independent $\mathrm{MS}^{\mathrm{E}}$ data analysis coupled to labelfree quantification software suggested that relative quantification of the proteins within BoNT progenitor toxins could be determined and would be very informative to further analysis of $C$. botulinum potency.

\section{Methods}

Materials and Safety Procedures

We purchased the BoNT/G complex from C. argentinense strain 89 from Metabiologics (Madison, WI). The company provided the complex at $1 \mathrm{mg} / \mathrm{mL}$ in 50 $\mathrm{mM}$ sodium citrate buffer, $\mathrm{pH} 5.5$ and quality control activated. The toxin activity in mouse LD50 or units $(\mathrm{U})$ of specific toxicity obtained from the provider was as follows: [3.3-3.6 $\left.\times 10^{\wedge} 6\right]$. We acquired all chemicals from Sigma-Aldrich (Saint Louis, MO), unless otherwise stated. Los Alamos National Laboratory (Los Alamos, NM) synthesized the substrate peptide used in the Endopep-MS assay. The peptide sequence is listed in Table 1 along with the targeted cleavage products. We followed standard safety handling and decontamination procedures, as described for botulinum neurotoxins [27]. We needed only very low toxin amounts for this work.

\section{Amino acid sequence comparisons}

We carried out all in silico work, including the sequence alignments, sequence identities, and phylogenetic trees, using Lasergene software (Protean, EditSeq, and
MegAlign ${ }^{\circledR}$-DNA Star Inc; Madison, WI). The alignments followed the Clustal W method [28]. We obtained the toxin protein sequences used for phenetic analysis of the seven BoNT serotypes, the 22 sequences, covering six subtypes, of/B toxin family, and the NAPs (NTNH, HA70 and HA17) of the seven BoNT serotypes from the NCBI protein database (March 2010). For the complete listing of all the accession numbers used in the toxin,/B subtypes, and the NAPs comparison, see additional files $1,2,3,4$, and 5 .

\section{One-dimensional sodium dodecyl sulphate/ polyacrylamide gel electrophoresis (1D SDS-PAGE)}

We added a $4 \mu \mathrm{L}$ aliquot of $[1 \mu \mathrm{g} / \mu \mathrm{L}]$ commercial BoNT/G complex to $2 \mu \mathrm{L}$ of NuPAGE ${ }^{\circledR}$ LDS sample buffer and $1 \mu \mathrm{L}$ NuPAGE ${ }^{\circledR}$ Reducing agent (Invitrogen; Carlsbad, CA) and reduced it by heating at $70^{\circ} \mathrm{C}$ for 10 min. We cooled and loaded the sample onto a $4-12 \%$ NuPAGE ${ }^{\circledR}$ Novex ${ }^{\circledR}$ Bis-Tris mini polyacrylamide gel (Invitrogen) and analyzed it alongside $10 \mu \mathrm{L}$ of Precision Plus: All Blue and Kaleidoscope protein pre-stained molecular weight markers (Bio-Rad, CA). We performed electrophoresis at $200 \mathrm{~V}$ for $35 \mathrm{~min}$, then rinsed the gel $3 \times 5$ min with $\mathrm{dH}_{2} \mathrm{O}$ and stained it with GelCode ${ }^{\mathrm{TM}}$ Blue Safe Protein Stain (Pierce; Rockford, IL) for $1 \mathrm{hr}$ before de-staining overnight in $\mathrm{dH}_{2} \mathrm{O}$.

\section{GeLC-MS/MS}

\section{Sample Excision}

We cut the sample lane of interest from a previously run 1D SDS-PAGE gel into $1 \times 2 \mathrm{~mm}$ slices-17 slices total-and stored the slices at $-80^{\circ} \mathrm{C}$ prior to tryptic digestion.

\section{Tryptic Digestion}

We lyophilized the individually cut and stored gel slices for 30 min by use of a Centrivap concentrator (Labconco; Kansas City, MO). We added $10 \mu \mathrm{L}$ of mass spectrometry-grade trypsin (Promega; Madison, WI) to each sample and incubated each sample at room temperature for $5 \mathrm{~min}$. We then added $25 \mu \mathrm{L}$ of digestion buffer ( $50 \mathrm{mM}$ ammonium bicarbonate: $1 \mathrm{mM} \mathrm{CaCl}_{2}$ ) to each sample and incubated the samples at $37^{\circ} \mathrm{C}$ overnight.

\section{Post-Digestion}

We added $5 \mu \mathrm{L}$ of $0.1 \%$ formic acid to the samples for acidification, followed by $2-3 \mathrm{~min}$ of sonication to release peptides. We then centrifuged the samples at 12 , $100 \times \mathrm{g}$ for $10 \mathrm{~min}$ to remove insoluble material. We collected the soluble peptide mixtures for nLC-MS/MS analysis.

\section{nLC-MS/MS analysis}

We obtained data by using a nanoAcquity ultra-performance liquid chromatography (nUPLC) coupled to a 
QTof-Premier MS system (Waters Corp; Milford, MA). We loaded protein digests onto a capillary reverse phase Symmetry $\mathrm{C}_{18}$ trapping column and a $\mathrm{BEH} \mathrm{C}_{18}$ analytical column $(100 \mu \mathrm{m}$ I.D. $\times 100 \mathrm{~mm}$ long, $1.7 \AA$ packing; Waters Corp) at a flow rate of $1.2 \mu \mathrm{L} / \mathrm{min}$. Each sample was separated by use of a 90 min gradient. The mobile phase solvents were (solvent A) $0.1 \%$ formic acid (FA; Thermo Scientific; Rockford, IL) in water (Burdick and Jackson; Muskegon, MI) and (solvent B) $0.1 \%$ FA in acetonitrile (ACN; Burdick and Jackson). The gradient profile consisted of a ramp from $1 \% \mathrm{~B}$ to $85 \% \mathrm{~B}$ over 82 min, followed by a second ramp to $1 \% \mathrm{~B}$ over $8 \mathrm{~min}$, with data acquired from 5 to $50 \mathrm{~min}$. We analyzed peptides by nano-electrospray on a QTof-Premier hybrid tandem mass spectrometer. The QTof used an $\mathrm{MS}^{\mathrm{E}}$ (or Protein Expression) method, which involved acquiring data-independent alternating low- and high-collision energy scans over the $m / z$ range 50-1990 in $0.6 \mathrm{sec}$, along with lockmass data on a separate channel to obtain accurate mass measurement.

\section{In solution Tryptic Digestion for nLC-MS/MS analysis}

We completed the tryptic digestions as previously described [25] with few modifications. In all cases, $5 \mu \mathrm{g}$ of commercial BoNT/G complex was digested, ending with a final digestion volume of $50 \mu \mathrm{L}$. All digestions were initially treated with an acid-labile surfactant (ALS) and performed at $52^{\circ} \mathrm{C}$ for 3 min following the addition of trypsin (Promega; Madison, WI). After acidification, the samples were centrifuged at $12,100 \times \mathrm{g}$ for $10 \mathrm{~min}$ to remove insoluble material. The soluble peptide mixtures were then collected for nLC-MS/MS analysis. Once the method was optimized, the experiment was repeated three times for two lots of commercial toxin (six digests total) to confirm that the results were consistent with the proteins that are expected in the toxin complex.

\section{$n L C-M S / M S$ analysis}

The in solution tryptic digests were analysed by use of two analytical instruments, a QTof-Premier and an LTQ-Orbitrap (Thermo-Finnigan; San Jose, CA), to help to improve the overall protein coverage of the BoNT/G complex. The analyses of digests that used the QTofPremier were performed initially as described above in the GeLC-MS/MS methods section.

\section{LTQ-Orbitrap}

Data were obtained by use of an Eksigent 2D nanoLC system (Eksigent Technologies; Dublin, CA) coupled to an LTQ-Orbitrap tandem mass spectrometer. A $365 \mu \mathrm{m}$ O.D. $\times 75 \mu \mathrm{m}$ I.D. fused silica pulled needle capillary (New Objective; Woburn, MA) was packed in house with $10 \mathrm{~cm}$ of $5 \mu \mathrm{m}$ Symmetry 300 reverse phase packing material (Waters Corp). The tryptic digests were loaded directly onto the analytical column without the use of a trap column. The peptide separation was performed over a 120 minute gradient at a flow rate of 400 $\mathrm{nl} / \mathrm{min}$. The mobile phase solvents were: (solvent A) $0.2 \%$ FA, $0.005 \%$ trifluoroacetic acid (TFA) in water, and (solvent B) $0.2 \% \mathrm{FA}, 0.005 \% \mathrm{TFA}$ in $\mathrm{ACN}$. The gradient was set at $5 \%$ B for 5 minutes, followed by a ramp to $30 \%$ B over 100 minutes, then a ramp up to $90 \%$ B in 5 min and held at $90 \%$ B for 2 min before returning to $5 \%$ $\mathrm{B}$ in $2 \mathrm{~min}$ and re-equilibration at $5 \% \mathrm{~B}$ for $20 \mathrm{~min}$. Peptides were analyzed by nano-electrospray on an LTQ Orbitrap hybrid tandem mass spectrometer. The mass spectrometer was programmed to perform data-dependent acquisition by scanning the mass range from $\mathrm{m} / \mathrm{z}$ 400 to 1600 at a nominal resolution setting of 60,000 for parent ion acquisition in the Orbitrap. Then, tandem mass spectra of doubly charged and higher charge state ions were acquired for the top 10 most intense ions. All tandem mass spectra were recorded by use of the linear ion trap. This process cycled continuously throughout the duration of the gradient.

\section{Endopep-MS analysis of toxin activity}

The reactions were performed as described previously [19] with a few modifications. In all cases, the final reaction volume was $20 \mu \mathrm{L}$; the final concentration of reaction buffer was $0.02 \mathrm{M}$ Hepes (pH 7.4), $10 \mathrm{mM}$ dithiothreitol, 0.2 $\mathrm{mM} \mathrm{ZnCl} \mathrm{Z}_{2}$, and $1 \mathrm{mg} / \mathrm{mL}$ bovine serum albumin (BSA); and the final concentration of the peptide substrate was 50 picomles $/ \mu \mathrm{L}$. For all experiments, $2 \mu \mathrm{L}[1 \mu \mathrm{g} / \mu \mathrm{L}]$ of BoNT/G complex was diluted with $\mathrm{dH}_{2} \mathrm{O}$ to various unit (U) concentrations; $1 \mu \mathrm{L}$ of each dilution was subsequently spiked into $20 \mu \mathrm{L}$ of reaction buffer and incubated at $37^{\circ} \mathrm{C}$, $42^{\circ} \mathrm{C}$, or $47^{\circ} \mathrm{C}$ for $10 \mathrm{~min}$, followed by $42^{\circ} \mathrm{C}$ for $120 \mathrm{hrs}$. Time points to gauge the progress of the reaction were taken at 6, 8, 24, 72, and 120 hrs (although in a few cases, a 96 or $144 \mathrm{hr}$ point was taken as a substitute for $120 \mathrm{hrs)}$ ). $2 \mu \mathrm{L}$ of each reaction was mixed with $18 \mu \mathrm{L}$ of $\alpha$-cyano-4hydroxycinnamic acid (CHCA) matrix and spotted for analysis by matrix-assisted laser desorption/ionizationtime of flight (MALDI-TOF) MS.

\section{MS Acquisition}

The Endopep-MS reactions were run on a 4800 MALDI-TOF (Applied Biosystems; Framingham, MA). Mass spectra of each sample well were obtained by scanning from 1000 to $4400 \mathrm{~m} / z$ in MS positive-ion reflector mode. The instrument uses a Nd:YAG laser at $337 \mathrm{~nm}$ with a $200 \mathrm{MHz}$ repetition rate, and each spectrum generated was an average of 2400 laser shots. Preceding each run, the instrument was tuned and calibrated for accurate MS analysis by use of a mixture of five peptides: des-Arg1-Bradykinin $(\mathrm{m} / \mathrm{z}$ 904.47), angiotensin I $(m / z 1,296.69)$, Glu1-fibrinopeptide B $(\mathrm{m} /$ $z 1,570.68)$, АCTH (1-17) $(m / z$ 2093.08), АCTH (18-39) $(m / z 2,465.20)$. 


\section{nLC-MS/MS and Endopep-MS data processing $n L C-M S / M S$ data}

Data obtained from the QTof-Premier were processed by use of Waters' ProteinLynx Global Server (PLGS v2.3; Milford, MA) and searched against a curated C. botulinum database consisting of 22, $000 \mathrm{NCBI}$ entries, including the protein standard Alcohol dehydrogenase (ADH, Waters Corp; Milford, MA) and contaminants such as trypsin. Tandem mass spectra were analyzed by use of the following parameters: variable modification of oxidized $M, 1 \%$ false positive rate, a minimum of three fragment ions per peptide and seven fragment ions per protein, a minimum of 1 peptide match per protein, and with up to two missed cleavages per peptide allowed. Root mean square mass accuracies were typically within $8 \mathrm{ppm}$ for the MS data and within $15 \mathrm{ppm}$ for MS/MS data.

Tandem mass spectra, obtained from the LTQ-Orbitrap, were extracted by Mascot Distiller (Matrix Science; London, UK; v2.2.1.0) and subsequently searched by use of Mascot (Matrix Science; v2.2.0) against a NCBI database consisting of seven million entries. All files generated by Mascot Distiller were searched with the following parameters: $200 \mathrm{ppm}$ parent MS ion window, $0.8 \mathrm{Da}$ MSMS ion window, and up to 2 missed cleavages allowed. Variable modifications for the Mascot searches were deamidation and oxidation.

Scaffold (Proteome Software Inc.; Portland, OR; v2.1.03) was used to validate all MS/MS-based peptide and protein identifications. Peptide identifications were accepted if they could be established at greater than $95.0 \%$ probability, as specified by the Peptide Prophet algorithm [29]. Protein identifications were accepted if they could be established at greater than $99.0 \%$ probability and if they contained at least two identified peptides. Protein probabilities were assigned by the Protein Prophet algorithm [30]. Proteins that contained similar peptides and that could not be differentiated on the basis of MS/MS analysis alone were grouped to satisfy the principles of parsimony. With the stringent parameters of Peptide Prophet and Protein Prophet, the false discovery rate was zero.

\section{Endopep-MS data}

The MS Reflector data, obtained from the Endopep-MS reactions, were analyzed by hand. A visual comparison (by an expert researcher) of the intact substrate and its cleavage products was enough to confirm a positive or negative reaction.

\section{Relative quantification of type G NAPs}

The six in solution digestions, three per lot of toxin, of BoNT/G complex were spiked with a known amount of standard yeast ADH digest (100 fMol on column) and analyzed as four technical replicates by use of the QTof-
Premier operated in data independent acquisition mode [31,32]. The relative protein quantification of individual replicates was determined based on the average MS signals of the three most intense tryptic peptides per protein, through use of the PLGS Identity ${ }^{\mathrm{E}}$ software. Once processed, the data sets were exported from PLGS and clustered according to digestion number for further evaluation by use of Excel (Microsoft Corporation, Redmond, WA). The femtomole and nanograms on column values (Table 2) were calculated by averaging the technical replicates, excluding outliers with $30 \%$ or greater variation. These values were then averaged on the basis of lot grouping. The lot grouping averaged values were used to determine a percent by weight, nanograms on column, and a percent of molecules, femtomole on column, of each protein within the BoNT/G complex. In addition, a molar ratio of BoNT:NTNH:HA70:HA17, and BoNT:NAPs, by weight, was determined.

\section{Additional material}

\begin{abstract}
Additional file 1: Protein sequence comparisons of toxin from the 7 BoNT serotypes. The seven BoNT serotypes toxin sequences (A-G; most common strains) were compared and it was determined that the BoNT/B serotype shared the most sequence similarity to/G. This figure depicts the percent of identity (top to bottom) and percent of divergence (left to right) of the protein sequences compared. Identity equals the percent of similarity the toxin sequences share and divergence the percent of difference between the toxin sequences.

Additional file 2: In-depth comparison of BoNT/G and/B subtypes. An in-depth comparison of/G and 22/B strains was completed to determine how similar/G was to the/B family. This figure depicts the percent of identity (top to bottom) and percent of divergence (left to right) of the protein sequences compared. Identity equals the percent of similarity the toxin sequences share and divergence the percent of difference between the toxin sequences.
\end{abstract}

Additional file 3: Protein sequence comparisons of NTNH from all 7 BoNT serotypes. The seven NTNH serotype toxin sequences (A-G; most common strains) were compared to determine which serotype shared the most sequence similarity to/G. This figure depicts the percent of identity (top to bottom) and percent of divergence (left to right) of the protein sequences compared. Identity equals the percent of similarity the toxin sequences share and divergence the percent of difference between the toxin sequences.

Additional file 4: Protein sequence comparisons of HA70 from all 7 BoNT serotypes. The seven HA70 serotype toxin sequences ( $A-G$; most common strains) were compared to determine which serotype shared the most sequence similarity to/G. This figure depicts the percent of identity (top to bottom) and percent of divergence (left to right) of the protein sequences compared. Identity equals the percent of similarity the toxin sequences share and divergence the percent of difference between the toxin sequences.

Additional file 5: Protein sequence comparisons of HA17 from all 7 BoNT serotypes. The seven BoNT serotype HA17 sequences (A-G; most common strains) were compared to determine which serotype shared the most sequence similarity to/G. This figure depicts the percent of identity (top to bottom) and percent of divergence (left to right) of the protein sequences compared. Identity equals the percent of similarity the toxin sequences share and divergence the percent of difference between the toxin sequences. 


\section{Acknowledgements}

The authors want to thank the members of the Biological Mass Spectrometry Laboratory at the National Center for Environmental Health, CDC for helpful discussions. This research was supported in part by an appointment to the Research Participation Program at the Centers for Disease Control and Prevention, administered by the Oak Ridge Institute for Science and Education through an interagency agreement between the U.S. Department of Energy and CDC.

In addition, this research was also supported in part by an appointment to the Emerging Infectious diseases (EID) fellowship program administered by the Association of Public Health Laboratories (APHL) and funded by the CDC.

References in this article to any specific commercial products, processes, services, manufacturers, or companies do not constitute an endorsement o a recommendation by the U.S. government or the CDC. The findings and conclusions in this report are those of the authors and do not necessarily represent the views of $C D C$.

\section{Author details}

${ }^{1}$ Centers for Disease Control and Prevention, National Center for Environmental Health, Division of Laboratory Sciences, 4770 Buford Hwy, N. E., Atlanta, GA 30341, USA. ${ }^{2}$ Association of Public Health Laboratories, 8515 Georgia Avenue, Suite 700, Silver Spring, MD 20910, USA. ${ }^{3}$ Oak Ridge Institute for Scientific Education, P.O. Box 117, Oak Ridge, TN 37831, USA.

\section{Authors' contributions}

RT helped with the experimental design, carried out experiments, data preparation and in silico proteomics analysis, created dendrograms and drafted the manuscript. HM initiated the project, conceived the whole study and experimental design, carried out experiments and contributed to interpretation and writing. AW contributed intellectually to experimental design, data analysis, bioinformatics and manuscript review. JR, DS and JB contributed intellectually to experimental design, data analysis, and manuscript review. All authors read and approved the final manuscript.

Received: 3 December 2010 Accepted: 18 October 2011 Published: 18 October 2011

\section{References}

1. Hill K, Xie G, Foley B, Smith T, Munk A, Bruce D, Smith L, Brettin T, Detter J: Recombination and insertion events involving the botulinum neurotoxin complex genes in Clostridium botulinum types $A, B, E$ and $F$ and Clostridium butyricum type E strains. BMC Biology 2009, 7:66.

2. Arnon SS, Schechter R, Inglesby TV, Henderson DA, Bartlett JG, Ascher MS, Eitzen E, Fine AD, Hauer J, Layton M, et al: Botulinum toxin as a biological weapon: medical and public health management. JAMA 2001, 285:1059-1070.

3. Smith LD: Botulism: The Organism, It's Toxins, The Disease Springfield: Charles C Thomas; 1977

4. Gimenez DF, Ciccarelli AS: Another type of Clostridium botulinum Zentralbl Bakteriol Orig 1970, 215:221-224.

5. Suen JC: Clostridium argentinese sp. nov.: a Genetically Homogeneous Group Composed of All Strains of Clostridium botulinum Toxin Type G and Some Nontoxigenic Strains Previously indentified as Clostridium subterminale or Clostridium hastiforme. Int J Syst Bacteriol 1988, 38:375-381.

6. Altwegg M, Hatheway CL: Multilocus enzyme electrophoresis of Clostridium argentinense (Clostridium botulinum toxin type $\mathrm{G}$ ) and phenotypically similar asaccharolytic clostridia. J Clin Microbiol 1988, 26:2447-2449

7. Hill KK, Smith TJ, Helma CH, Ticknor LO, Foley BT, Svensson RT, Brown JL, Johnson EA, Smith LA, Okinaka RT, et al: Genetic diversity among Botulinum Neurotoxin-producing clostridial strains. J Bacteriol 2007, 189:818-832.

8. Lewis GE, Kulinski SS, Reichard DW, Metzger JF: Detection of Clostridium botulinum type $\mathrm{G}$ toxin by enzyme-linked immunosorbent assay. Appl Environ Microbiol 1981, 42:1018-1022.

9. Glasby C, Hatheway CL: Fluorescent-antibody reagents for the identification of Clostridium botulinum. J Clin Microbiol 1983, 18:1378-1383.

10. Bhandari M, Campbell KD, Collins MD, East AK: Molecular characterization of the clusters of genes encoding the botulinum neurotoxin complex in clostridium botulinum (Clostridium argentinense) type $\mathrm{G}$ and nonproteolytic Clostridium botulinum type B. Curr Microbiol 1997, 35:207-214.

11. Raffestin S, Marvaud J, Cerrato R, Dupuy B, Popoff M: Organization and regulation of the neurotoxin genes in Clostridium botulinum and Clostridium tetani. Anaerobe 2004, 10:93-100.

12. Sharma SK, Singh BR: Hemagglutinin binding mediated protection of botulinum neurotoxin from proteolysis. J Nat Toxins 1998, 7:239-253.

13. Schiavo G, Malizio C, Trimble WS, de Laureto PP, Milan G, Sugiyama H, Johnson EA, Montecucco C: Botulinum G neurotoxin cleaves VAMP/ synaptobrevin at a single Ala-Ala peptide bond. J Biol Chem 1994, 269:20213-20216.

14. Sonnabend WF, Sonnabend UP, Krech T: Isolation of Clostridium botulinum type $\mathrm{G}$ from Swiss soil specimens by using sequential steps in an identification scheme. Appl Environ Microbiol 1987, 53:1880-1884.

15. Ciccarelli AS, Whaley DN, McCroskey LM, Gimenez DF, Dowell VR, Hatheway CL: Cultural and physiological characteristics of Clostridium botulinum type $\mathrm{G}$ and the susceptibility of certain animals to its toxin Appl Environ Microbiol 1977, 34:843-848.

16. Eklund MW, Poysky FT, Mseitif LM, Strom MS: Evidence for plasmidmediated toxin and bacteriocin production in Clostridium botulinum type G. Appl Environ Microbiol 1988, 54:1405-1408.

17. Zhou Y, Sugiyama $H$, Nakano $H$, Johnson EA: The genes for the Clostridium botulinum type $\mathrm{G}$ toxin complex are on a plasmid. Infect Immun 1995, 63:2087-2091.

18. Hines H, Lebeda F, Hale M, Brueggemann E: Characterization of botulinum progenitor toxins by mass spectrometry. Appl Environ Microbiol 2005, 71:4478-4486.

19. Boyer AE, Moura H, Woolfitt AR, Kalb SR, McWilliams LG, Pavlopoulos A, Schmidt JG, Ashley DL, Barr JR: From the mouse to the mass spectrometer: detection and differentiation of the endoproteinase activities of botulinum neurotoxins A-G by mass spectrometry. Anal Chem 2005, 77:3916-3924.

20. Deery MJ, Maywood ES, Chesham JE, Sladek M, Karp NA, Green EW, Charles PD, Reddy AB, Kyriacou CP, Lilley KS, et al: Proteomic analysis reveals the role of synaptic vesicle cycling in sustaining the suprachiasmatic circadian clock. Curr Biol 2009, 19:2031-2036.

21. Welham NV, Marriott G, Tateya I, Bless DM: Proteomic changes in rat thyroarytenoid muscle induced by botulinum neurotoxin injection. Proteomics 2008, 8:1933-1944.

22. Muetzelburg MV, Hofmann F, Just I, Pich A: Identification of biomarkers indicating cellular changes after treatment of neuronal cells with the C3 exoenzyme from Clostridium botulinum using the iTRAQ protocol and LC-MS/MS analysis. J Chromatogr B Analyt Technol Biomed Life Sci 2009, 877:1344-1351

23. Campbell K, Collins MD, East AK: Nucleotide sequence of the gene coding for Clostridium botulinum (Clostridium argentinense) type $\mathrm{G}$ neurotoxin: genealogical comparison with other clostridial neurotoxins. Biochim Biophys Acta 1993, 1216:487-491.

24. Stenmark P, Dong M, Dupuy J, Chapman ER, Stevens RC: Crystal Structure of the Botulinum Neurotoxin Type G Binding Domain: Insight into Cell Surface Binding. J Mol Biol 2010, 397:1287-1297.

25. Norrgran J, Williams TL, Woolfitt AR, Solano MI, Pirkle JL, Barr JR: Optimization of digestion parameters for protein quantification. Anal Biochem 2009, 393:48-55.

26. Turapov O, Mukamolova G, Bottrill A, Pangburn M: Digestion of native proteins for proteomics using a thermocycler. Anal Chem 2008, 80:6093-6099

27. Centers for Disease Control and Prevention (CDC): Botulism in the United States, 1899-1996, handbook for epidemiologists, clinicians, and laboratory workers Atlanta, GA: CDC; 1998.

28. Thompson JD, Higgins DG, Gibson TJ: CLUSTAL W: improving the sensitivity of progressive multiple sequence alignment through sequence weighting, position-specific gap penalties and weight matrix choice. Nucleic Acids Res 1994, 22:4673-4680

29. Keller A, Nesvizhskii A, Kolker E, Aebersold R: Empirical statistical model to estimate the accuracy of peptide identifications made by MS/MS and database search. Anal Chem 2002, 74:5383-5392.

30. Nesvizhskii A, Keller A, Kolker E, Aebersold R: A statistical model for identifying proteins by tandem mass spectrometry. Anal Chem 2003, 75:4646-4658. 
31. Silva J, Denny R, Dorschel C, Gorenstein M, Li G-Z, Richardson K, Wall D, Geromanos S: Simultaneous qualitative and quantitative analysis of the Escherichia coli proteome: a sweet tale. Mol Cell Proteomics 2006, 5:589-607.

32. Geromanos S, Vissers JPC, Silva J, Dorschel C, Li G-Z, Gorenstein M, Bateman R, Langridge J: The detection, correlation, and comparison of peptide precursor and product ions from data independent LC-MS with data dependant LC-MS/MS. Proteomics 2009, 9:1683-1695.

doi:10.1186/1471-2180-11-232

Cite this article as: Terilli et al: A historical and proteomic analysis of botulinum neurotoxin type/G. BMC Microbiology 2011 11:232.

Submit your next manuscript to BioMed Central and take full advantage of:

- Convenient online submission

- Thorough peer review

- No space constraints or color figure charges

- Immediate publication on acceptance

- Inclusion in PubMed, CAS, Scopus and Google Scholar

- Research which is freely available for redistribution

Submit your manuscript at www.biomedcentral.com/submit 